\title{
Surface-enhanced Raman scattering detection of silver nanoparticles in environmental and biological samples
}

\author{
Huiyuan Guo, ${ }^{\mathrm{a}}$ Baoshan Xing, ${ }^{\mathrm{a}, *}$ Leigh C. Hamlet, ${ }^{\mathrm{a}}$ Andrea Chica, ${ }^{\mathrm{a}}$ Lili He ${ }^{\mathrm{b}, *}$ \\ ${ }^{a}$ Stockbridge School of Agriculture, University of Massachusetts, Amherst, MA 01003, USA \\ ${ }^{\mathrm{b}}$ Department of Food Science, University of Massachusetts, Amherst, MA 01003, USA
}

Corresponding Authors

*Dr. Baoshan Xing, Tel.: +1 413545 5212; Fax: +1 413577 0242; E-mail: bx@umass.edu

*Dr. Lili He, Tel.: +1 413545 5847; Fax: +1 413545 1262; E-mail: lilihe@foodsci.umass.edu 


\section{Abstract}

Growing concerns over the potential release and threat of silver nanoparticles (AgNPs) to environmental and biological systems urge researchers to investigate their fate and behavior. However, current analytical techniques cannot meet the requirements for rapidly, sensitively and reliably probing AgNPs in complex matrices. Surface-enhanced Raman spectroscopy (SERS) has shown great capability for rapid detection of AgNPs based on an indicator molecule that can bind on the AgNP surface. The objective of this study was to exploit SERS to detect AgNPs in environmental and biological samples through optimizing the Raman indicator for SERS. Seven indicator molecules were selected and determined to obtain their SERS signals at optimal concentrations. Among them, 1,2-Di(4-pyridyl)ethylene (BPE), crystal violet and ferric dimethyl-dithiocarbamate (ferbam) produced the highest SERS intensities. Further experiments on binding competition between each two of the three candidates showed that ferbam had the highest AgNPs-binding ability. The underlying mechanism lies in the strong binding affinity of ferbam with AgNPs via multiple sulfur atoms. We further validated ferbam to be an effective indicator for SERS detection of as low as $0.1 \mathrm{mg} / \mathrm{L}$ AgNPs in genuine surface water and 0.57 $\mathrm{mg} / \mathrm{L}$ in spinach juice. Moreover, limited interference on SERS detection of AgNPs was found from environmentally relevant inorganic ions, organic matter, inorganic particles, as well as biologically relevant components, demonstrating the ferbam-assisted SERS is an effective and sensitive method to detect AgNPs in complex environmental and biological samples.

\section{Keywords}

SERS, AgNPs, environmental water, biological samples, matrix components 


\section{Introduction}

Silver nanoparticles (AgNPs) have raised concerns over their potential threat to human health and the environment due to their increasing applications and potential toxicity (Bartłomiejczyk et al., 2013; Kim and Ryu, 2013; Schluesener and Schluesener, 2013; Wijnhoven et al., 2009). Among nanotechnology-based consumer products on the market, the number of products containing AgNPs are the largest (www.nanotechproject.org). Currently in the US, there are more than 110 officially registered silver containing pesticides used for medical, agricultural, environmental and home purposes (Bergeson, 2010). Many of the registered pesticides contain nanosilver. The widespread use of AgNPs is mainly due to their higher antimicrobial activity relative to the bulk silver particles. However, the large scale applications of AgNPs increase the likelihood of human exposure and highlight the importance of thoroughly understanding AgNP fate and effects in biological systems. For example, if AgNPs are taken up by plants, further bioaccumulation into higher trophic level organisms may be initiated, which can affect the entire food chain and pose risks to humans and other organisms (Gardea-Torresdey et al., 2014; Hawthorne et al., 2014). So far, AgNPs-induced risks, such as oxidative stress, genotoxicity and apoptosis in human cells have been reported by a number of studies (Bartłomiejczyk et al., 2013; Kim and Ryu, 2013). For example, AgNPs (5-10 nm) ranging from $0.05 \mathrm{mg} / \mathrm{L}$ to $0.2 \mathrm{mg} / \mathrm{L}$ could lead to oxidative stress, DNA damage, cell cycle arrest and apoptosis in human jurkat cells after $24 \mathrm{~h}$ treatment (Eom and Choi, 2010). Therefore, it is important to assess the levels of AgNPs in food, agricultural and environmental samples.

However, most current techniques for characterizing and detecting AgNPs have various problems (Majedi and Lee, 2016; Tiede et al., 2008). Electron microscopy techniques, such as scanning electron microscopy (SEM) and transmission electron microscopy (TEM), have been used to image the size and morphology of AgNPs. However, these techniques require 
complicated sample preparation procedures, especially for biological samples. Also, they cannot identify silver species unless they are coupled with energy dispersive X-ray spectroscopy (EDS). In other words, SEM and TEM results cannot be reliably used for interpreting and predicting the environmental behavior and toxicity of AgNPs, which are chemically reactive and can undergo various transformations in the environment (Levard et al., 2012). Dispersive light scattering (DLS) and UV-vis spectroscopy can characterize AgNPs but the results may be interfered by sample matrices. Several elemental quantification techniques, including graphite furnace atomic absorption spectrometry (GFAA), inductively coupled plasma optical emission spectrometry (ICP-OES) or inductively coupled plasma mass spectrometry (ICP-MS), are capable to measure total Ag concentration, but they fail to provide the speciation information of Ag. Currently, more advanced techniques, such as single particle inductively coupled plasma mass spectrometry (spICP-MS) and asymmetric flow field flow fractionation ICP-MS (AF4-ICP-MS), have been developed to straightforwardly monitor different forms of AgNPs in simple water samples. However, their sensitivity may be mitigated in terms of low concentrations of AgNPs in complex samples (Mwilu et al., 2014). Overall, three main bottlenecks are faced by current techniques: complex sample preparation, difficulty in differentiating AgNPs from other Ag species and matrix interferences. Therefore, reliable analytical methods that can meet these challenges are urgently needed.

SERS is an advanced technique that incorporates nanoscale noble metal substrates into normal Raman spectroscopy. Weak Raman signals can be improved by many orders of magnitude because the excitation of localized surface plasmon resonance (LSPR) on nanoscale-roughened surfaces can generate a large electromagnetic field which increases the Raman cross section from the molecules adsorbed to noble metal nanostructures (Haynes et al., 2005). While most 
researchers utilized nano silver as the substrate of SERS to analyze chemical or biological analytes, we applied SERS in an opposite way, i.e., use a compound that can bind onto the AgNPs and produce characteristic signals to indicate the presence of AgNPs. Since SERS intensity is dependent on the inherent properties of the ligand molecules as well as the interaction between AgNPs and ligands, the indicator selection is the key to develop a sensitive and effective method for analysing AgNPs in complex matrices. A good indicator should 1) produce distinct signals with high intensity at low concentrations upon mixing with AgNPs, and 2) have very strong affinity to the AgNP surface so that it can outcompete with other molecules in the sample for adsorbing on the NP surfaces or replace any ligand already on the surface of AgNPs. To date, the ability of SERS method to quantify AgNPs has not been investigated in complex sample matrices, such as environmental water and biological samples. Whether SERS method could accurately identify AgNPs in complex matrices is dependent on if the indicator could locate and adsorb onto AgNPs in the presence of potentially interfering matrix components.

Here in this study, we aimed to experimentally select and validate the best SERS indicator and further applied the indicator-assisted SERS method to detect AgNPs in real environmental and biological samples (i.e., surface water and spinach leaves). Furthermore, a detailed analysis of the matrix effects on AgNP detection by SERS was performed. As far as we know, this is the first time that the abilities of different indicator molecules for detecting AgNPs were evaluated and the indicator-assisted SERS was applied to quantify AgNPs in both environmental and biological samples, with a thorough investigation of potential interfering effects of matrix components.

\section{Materials and methods}




\section{Materials}

Acetone ( $\geq 99.5 \%), \mathrm{AgNO}_{3}$ (99.8\%), ferbam, melamine (99\%), sodium citrate, sodium bicarbonate, sodium sulfate anhydrous, sodium chloride, titanium oxide (98.0-100.5\%) and Au slides (for SERS) were all obtained from Fisher Scientific (Pittsburgh, PA). Sodium carbonate anhydrous was ordered from J.T. Baker (Center Valley, PA). Crystal violet, rhodamine 6G (R6G, 99\%), 1,2-Di(4-pyridyl)ethylene (BPE, $18.223 \mathrm{mg} / \mathrm{L}$ ) and humic acid (sodium salt) were purchased from Sigma-Aldrich (St. Louis, MO) while selenium dimethyldithiocarbamate was purchased from Gelest (Morrisville, PA) and ruthenium red (99.9\%) was obtained from Pfaltz \& Bauer (Waterbury, CT).

Pond water was collected from University of Massachusetts Amherst in October, 2014. A total carbon analyzer (Shimadzu, TOC-L) was used to measure inorganic carbon content and total organic carbon content (TOC) in the pond water sample. A conductivity/pH meter (Fisher Scientific, XL200) was used to determine electrical conductivity (EC) and pH of the water sample. To analyze the total solid concentration, $50 \mathrm{~mL}$ of water sample was placed into a clean dish and dried in an oven at $100{ }^{\circ} \mathrm{C}$ for $24 \mathrm{~h}$. The mass difference between the clean dish and the dried dish with residue was calculated to represent the total solid concentration. Fresh spinach leaves were purchased from a local supermarket (Stop \& Shop, Hadley, MA).

\section{Methods}

\subsection{Assessment of the SERS intensity of indicator molecules}

To our knowledge, various dye molecules with a conjugated double bond system are very Raman active (producing high intensity peaks at low concentrations). They have been widely used in various sensors or probes for cellular and molecular diagnostics by incorporating them on or in the NPs (Huh et al., 2009). Also, molecules with multiple sulfur or nitrogen atoms can bind Au 
and Ag strongly and are widely used for surface modifications of Au or Ag substrate to improve their functionalities (Doering and Nie, 2003; Graham et al., 2001). Accordingly, we chose seven potentially good candidates which are dyes and/or contain multiple pyridyl, sulfur or nitrogen atoms: ferbam, crystal violet, rhodamine 6G (R6G), melamine, 1,2-Di(4-pyridyl)ethylene (BPE), selenium dimethyldithiocarbamate, and ruthenium red. Their chemical structures can be found in Fig. 1.

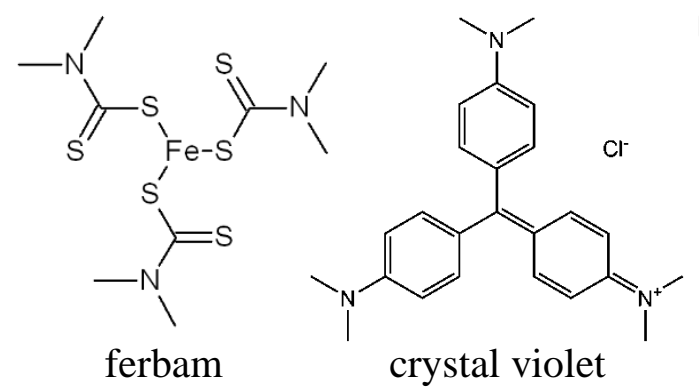<smiles>CCN=c1cc2oc3cc(NCC)c(C)cc3c(-c3ccccc3C(=O)OCC)c-2cc1C</smiles>

rhodamine 6G<smiles>Nc1nc(N)nc(N)n1</smiles>

melamine

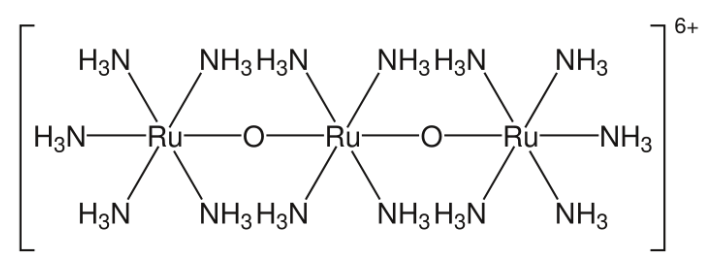

ruthenium red<smiles>C(=C/c1ccncc1)\c1ccncc1</smiles>

1,2-Di(4-pyridyl)ethylene

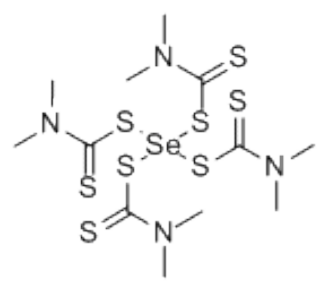

selenium dimethyldithiocarbamate

Fig. 1. Chemical structures of 7 indicators

In order to measure the SERS intensity of individual indicators, a previously published method was used (Guo et al., 2015). Briefly, 20 mg/L AgNPs (citrate coated, 60 nm, NanoComposix) were mixed with each indicator at a volume ratio of 3:17. After 45 min incubation on a $24 \mathrm{rpm}$ Nutating mixer (Fisher Scientific) at room temperature $\left(25^{\circ} \mathrm{C}\right)$, the mixture was centrifuged at 10,000 rpm for 5 min to settle down AgNPs-indicator complexes to the bottom of the tube. The precipitates were then pipetted onto a gold slide and dried in a fume hood. After drying, the 
samples were immediately detected by a DXR Raman Spectro-microscope (Thermo Scientific, Madison, WI), which consisted of a 780-nm laser with an output power of $5 \mathrm{~mW}$, a $10 \times$ confocal microscope objective with $3 \mu \mathrm{m}$ spot diameter and $5 \mathrm{~cm}^{-1}$ spectral resolution, as well as a $50 \mu \mathrm{m}$ slit width for $2 \mathrm{~s}$ integration time. The detection process was monitored using the OMNIC ${ }^{\mathrm{TM}}$ software (version 9.1). Ten spectra from each sample were chosen and averaged to a final spectrum using TQ Analyst software (version 8.0, Thermo Scientific).

\subsection{Evaluation of the binding affinities of indicator molecules}

The best indicator should be sensitive enough to indicate the presence of AgNPs, even when the concentration of AgNPs is low. Therefore, we selected 3 indicators of the highest signal intensities among the 7 tested ones as the candidates and compared their binding affinities to AgNPs. The method for binding competition (Fig. 2) involved mixing AgNPs ( 100 mg/L and $\sim 70 \mathrm{~nm}$, synthesized using the method by Lee and Meisel (1982)) with each two of the three indicators $\left(10^{-4} \mathrm{M}\right)$ at a volume ratio of 2:1:1, incubation for $45 \mathrm{~min}$ on the 24 rpm Nutating mixer, and then centrifugation for 4 times. The centrifugation was carried out at 10,000 rpm for 5 min each time. For the first 3 times, the supernatant was removed and nanopure water was refilled in order to completely wash away the indicator molecules that were not bound to the surface of AgNPs. After the fourth centrifugation, the sediments at the tube bottom were pipetted onto a gold slide and air dried for Raman measurement with the same settings. Higher amount of AgNPs was used to make sure after 3 times of washing, the concentration of AgNPs was still high enough to enhance the signals of the binding molecule. Individual indicators used as controls were treated the same as those in competitive experiments. 


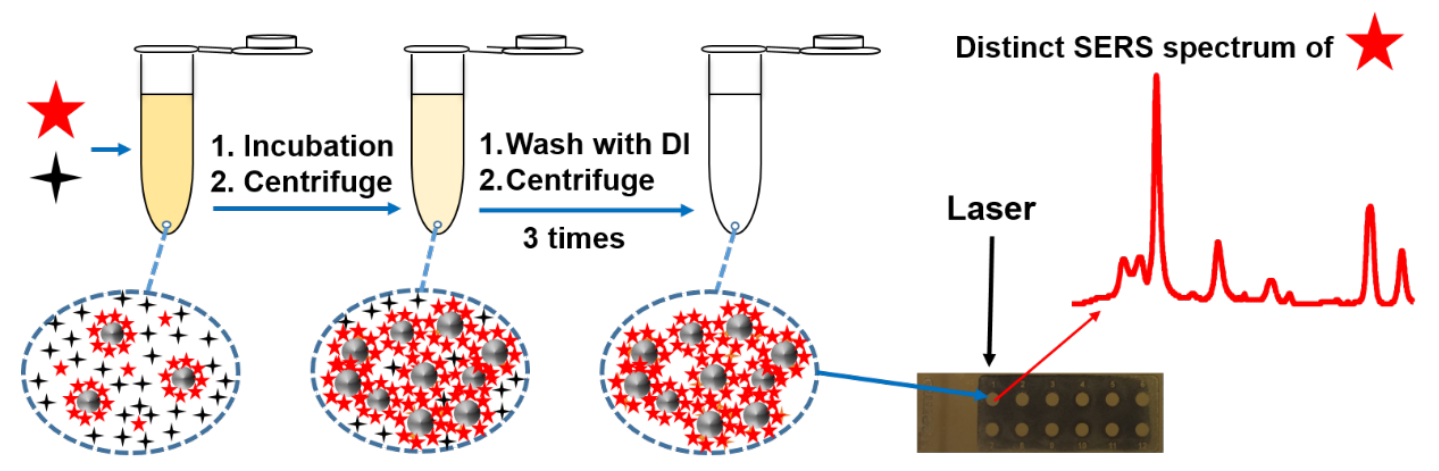

Indicator with higher binding affinity $($ AgNPs

Indicator with lower binding affinity

Fig. 2. Schematic diagram illustrating the selection of an indicator with stronger binding affinity.

\subsection{Validation of the best indicator by detecting AgNPs in aqueous environmental and biological samples}

To simulate AgNPs-contaminated environmental water, pond water was spiked with AgNPs (citrate coated, $60 \mathrm{~nm}$, NanoComposix). Pond water containing different concentrations of AgNPs was mixed with $2.4 \times 10^{-5} \mathrm{M}$ ferbam at a volume ratio of 3:17. The following steps were the same as the testing of individual indicators. Pond water alone or pond water with sodium citrate (the AgNP solvent) were used as controls and followed the same treatment procedures as individual indicators.

Further, we evaluated the ability of ferbam-assisted SERS approach to detect AgNPs in biological matrix. Fresh spinach leaves were liquefied using a blender and mixed with AgNPs (citrate coated, $60 \mathrm{~nm}$, NanoComposix). The mixtures containing different concentrations of AgNPs were detected using the same method as AgNPs-containing pond water.

\subsection{Effect of matrix components on the detection of AgNPs by ferbam-assisted SERS}

In addition to detecting AgNPs in real environmental or biological samples, we also investigate the effects of specific matrix components on SERS analysis of AgNPs. For environmental water 
matrices, we mainly tested inorganic ions $\left(\mathrm{Cl}^{-}, \mathrm{SO}_{4}{ }^{2-}, \mathrm{CO}_{3}{ }^{2-}\right.$, and $\mathrm{HCO}_{3}{ }^{-}$), organic matter (humic acid) and inorganic solids $\left(\mathrm{TiO}_{2}\right)$. For biological matrices, we used protein and pigments (chlorophyll and carotenes) which were separately extracted from spinach using the published methods in the literature (Pavia et al., 1999; Wang et al., 2006). The concentrations of matrix components were chosen to be close or higher than the environmentally relevant levels. The background chloride levels in fresh water are within the range of 1-250 mg/L (Johnson et al., 2011). Chloride at $177 \mathrm{mg} / \mathrm{L}$ was used in this study. The typical level of sulfate in fresh water falls around $20 \mathrm{mg} / \mathrm{L}$ and ranges from 2 to $250 \mathrm{mg} / \mathrm{L}$ in lakes (WHO, 2004). Therefore, 480 $\mathrm{mg} / \mathrm{L}$, as we used in this study, is high enough to test the tolerance of SERS method to sulfate. The average concentration of carbonate in fresh water is $58 \mathrm{mg} / \mathrm{L}$ (Lower, 1999). In this study a much higher concentration (300 $\mathrm{mg} / \mathrm{L}$ ) of carbonate was used to test the interference of carbonate on SERS detection of AgNPs. Similarly, the bicarbonate concentration applied in this study was $305 \mathrm{mg} / \mathrm{L}$ based on the fact that the levels of bicarbonate in surface freshwater are usually no more than $250 \mathrm{mg} / \mathrm{L}$ (Nikanorov et al., 2009). The typical level of natural organic matter in surface water is from $0.1 \mathrm{mg} / \mathrm{L}$ to $20 \mathrm{mg} / \mathrm{L}$ and the major components are humic substances (Rodrigues et al., 2009). Here, $20 \mathrm{mg} / \mathrm{L}$ humic acid was used to represent the humic substances expected in real aquatic systems. The concentration of $\mathrm{TiO}_{2}$ particles was set as 50 mg/L, which aims to simulate a cloudy water sample (Michigan Department of Environmental Quality, 1994). Samples containing $1 \mathrm{mg} / \mathrm{L}$ AgNPs in different matrix constituents were analyzed using ferbam-assisted SERS. The signal intensities were compared with a control without any matrix constituents. The statistical significance of differences between the control and different matrix components was determined by one-way analysis of variance (One-way ANOVA) followed by Dunnett's test. The difference is considered significant when $p \leq 0.05$. 


\section{Results and discussion}

\subsection{Assessment of the SERS intensity of indicator molecules}

In order to show which indicator has the strongest SERS response, we used a series of concentrations of each indicator to screen the optimum concentration that produced the highest SERS intensity. As evident in Fig. S1, the signals from ferbam were strongest when the concentration was $2.4 \times 10^{-5} \mathrm{M}$. We also recorded the optimum concentrations of the other six indicators and corresponding Raman intensities of the highest peaks (Table 1, Fig. S2-S5). At the optimum concentrations, the peak intensity sequence of all indicators is: BPE $>$ ferbam $>$ crystal violet $>$ R6G $>$ melamine $>$ ruthenium red $>$ selenium dimethyldithiocarbamate. Accordingly, the first three with highest peak intensities were selected as potential good indicators.

Table 1. Highest signal positions and intensities of 7 indicators at their respective optimum concentrations. The best three (marked in red) were chosen to evaluate their binding affinities with AgNPs.

\begin{tabular}{|c|c|c|c|}
\hline Indicator & $\begin{array}{l}\text { Optimum } \\
\text { concentration }\end{array}$ & $\begin{array}{l}\text { Highest signal } \\
\text { position }\end{array}$ & $\begin{array}{l}\text { Highest signal } \\
\text { intensity }\end{array}$ \\
\hline Ferbam & $2.4 \times 10^{-5} \mathrm{M}$ & $1382 \mathrm{~cm}^{-1}$ & 23980 \\
\hline Crystal violet & $10^{-4} \mathrm{M}$ & $1621 \mathrm{~cm}^{-1}$ & 22460 \\
\hline R6G & $10^{-4} \mathrm{M}$ & $1511 \mathrm{~cm}^{-1}$ & 16600 \\
\hline Melamine & $10^{-3} \mathrm{M}$ & $701 \mathrm{~cm}^{-1}$ & 12860 \\
\hline BPE & $10^{-4} \mathrm{M}$ & $1641 \mathrm{~cm}^{-1}$ & 58270 \\
\hline $\begin{array}{l}\text { Selenium } \\
\text { dimethyldithiocarbamate }\end{array}$ & $10^{-6} \mathrm{M}$ & $1382 \mathrm{~cm}^{-1}$ & 9848 \\
\hline Ruthenium red & $1.3 \times 10^{-5} \mathrm{M}$ & $752 \mathrm{~cm}^{-1}$ & 10450 \\
\hline
\end{tabular}




\subsection{Evaluation of the binding affinities of indicator molecules}

Fig. 3 shows the comparisons of binding affinities of three candidate indicators. When ferbam and BPE were both present in the AgNPs-containing system, the spectrum displayed the characteristic signals of ferbam, indicating that ferbam bound to AgNPs more strongly than BPE. Similarly, the mixture of crystal violet and BPE showed the spectrum pattern of crystal violet, indicating that crystal violet outcompeted BPE in forming complexes with AgNPs. Further competition between ferbam and crystal violet demonstrates that ferbam had the strongest binding ability with AgNPs among the three indicators. This set of data proved that experimentally ferbam can successfully compete with other candidates (i.e., BPE and crystal violet) on binding to the surface of AgNPs. The reason that ferbam can outcompete BPE and cystal violet is due to the stronger binding affinity of multiple sulfur atoms in ferbam to the AgNPs than that of the pyridyl nitrogen atoms in BPE and nitrogen atoms in crystal violet (Guo et al., 2016; Sánchez-Cortés et al., 1998; Zheng et al., 2013). 


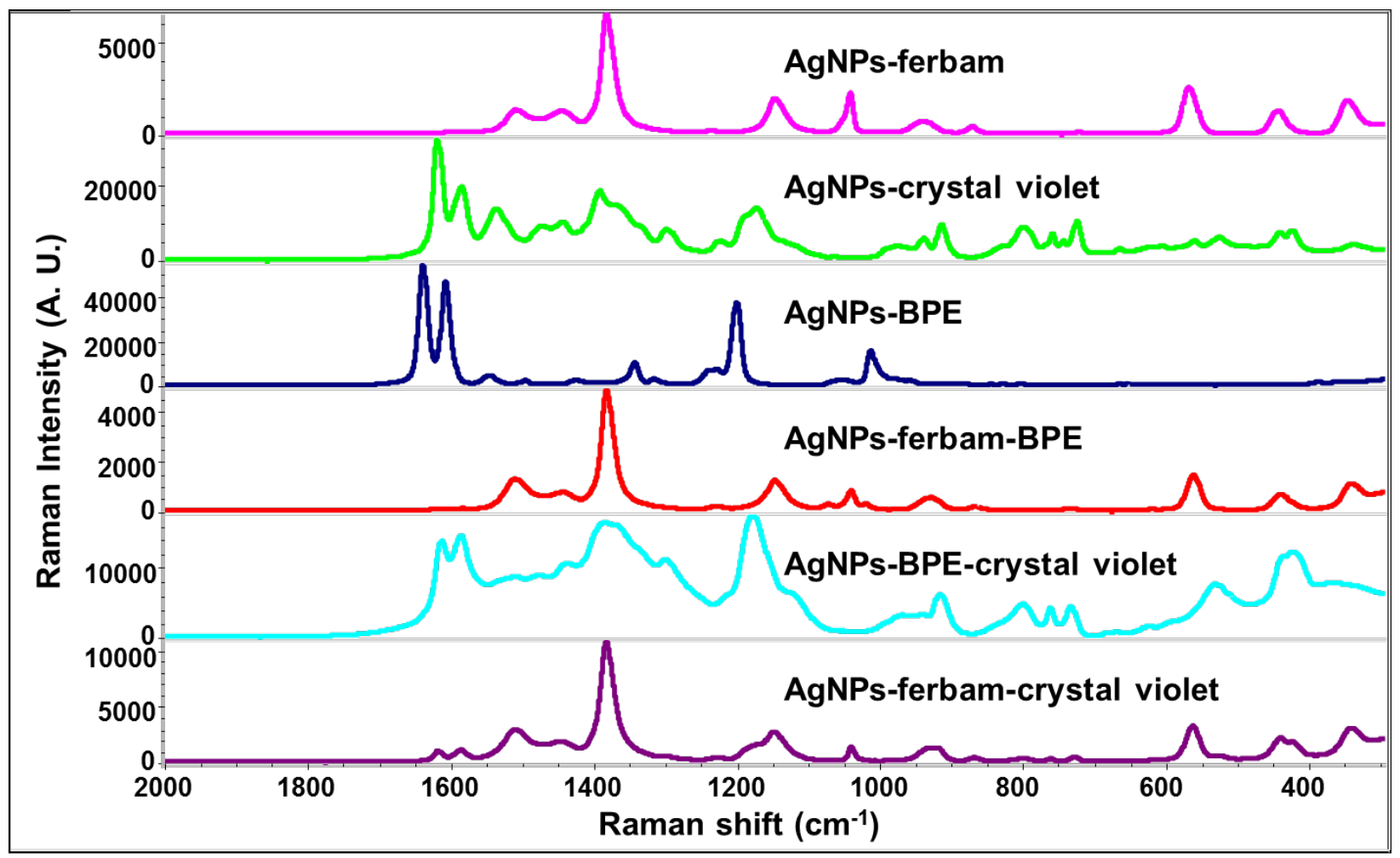

Fig. 3. Comparisons of binding affinities of 3 candidate indicators. Based on the peak characterization, ferbam>crystal violet>BPE in their binding affinities to AgNPs.

\subsection{Validation of the ferbam-assisted SERS method for detecting AgNPs in aqueous environment and biological samples}

In order to validate the capability of ferbam to signify the presence of AgNPs in real environmental samples, we spiked AgNPs (citrate coated, $60 \mathrm{~nm}$, NanoComposix) with pond water to achieve desired AgNP concentrations and detected them in the resulting mixtures using ferbam-assisted SERS method. Data in Fig. 4 suggested that compared with pond water alone or pond water plus ferbam, AgNPs-containing pond water plus ferbam showed the distinct signals of ferbam, demonstrating the enhancement effect caused by the presence of AgNPs. Evidently, the characteristic peaks of ferbam (e.g. $1382 \mathrm{~cm}^{-1}$ and $1147 \mathrm{~cm}^{-1}$ ) increased as AgNP concentration increased from $0 \mathrm{mg} / \mathrm{L}$ to $10 \mathrm{mg} / \mathrm{L}$. The linear relationship between Raman 
intensity at $1382 \mathrm{~cm}^{-1}$ and AgNP concentration reflected the potential of ferbam-assisted SERS method to quantify AgNPs in environmental waters. Moreover, ferbam could attach to AgNPs strongly even in the presence of matrix substances (e.g., natural organic matter, inorganic anions and solids, Table S1) in the real water. To confirm this, we added individual of aqueous substances into the test samples. The inorganic ions we chose were $\mathrm{Cl}^{-}, \mathrm{SO}_{4}{ }^{2-}, \mathrm{CO}_{3}{ }^{2-}$, and $\mathrm{HCO}_{3}{ }^{-}$, which are commonly present in natural waters and may affect the detection of AgNPs. As shown in Fig. 5, none of the components decreased the SERS signals. Specifically, the detection of AgNPs was not significantly affected by inorganic ions and humic acid (ANOVA, Dunnett's test, $p<0.05)$. In addition, $\mathrm{TiO}_{2}$ particles increased the signals of AgNPs in a significant manner. The zeta potential $(-32.84 \pm 1.04)$ of $\mathrm{TiO}_{2}$ particles shows they were negatively charged, which excludes the possibility of heteroaggregation arising from the electrostatic attraction of AgNPs by $\mathrm{TiO}_{2}$ particles. The enhancement is likely due to the fact that when the $\mathrm{TiO}_{2}$ particles $(73.2$ $180.9 \mathrm{~nm}$, average diameter $113.6 \pm 23.8 \mathrm{~nm}$, Fig. S6) larger than AgNPs, aggregated during centrifugation, AgNPs filled up the gaps/pores between the $\mathrm{TiO}_{2}$ particles and created more hot spots due to the physical enrichment. In the future, a systematic examination of the effects of various suspended particles on the detection of AgNPs by SERS should be performed in order to show the relationship between the properties of suspended solids and SERS signals of AgNPs in environmental waters. 

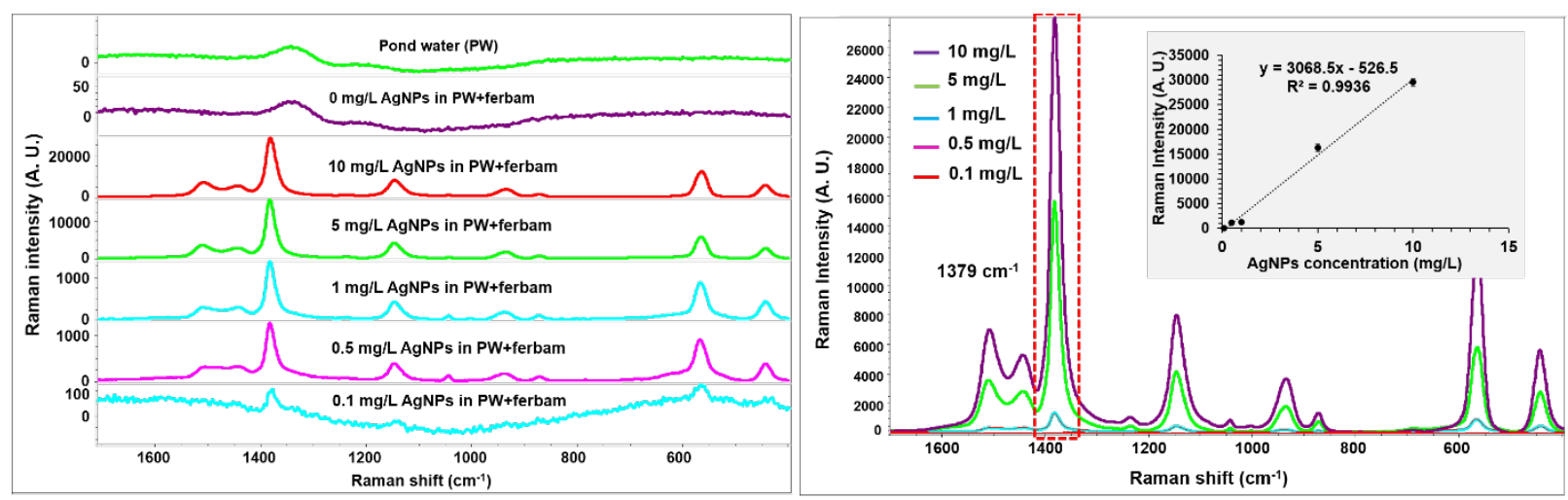

Fig. 4. SERS spectra of different concentrations of AgNPs in pond water after incubating with ferbam (Left) and the linear relationship between Raman intensity at $1382 \mathrm{~cm}^{-1}$ and AgNPs concentration (Right). Pond water alone and pond water with the capping solution of AgNPs (2 mM sodium citrate) plus ferbam were used as controls. 

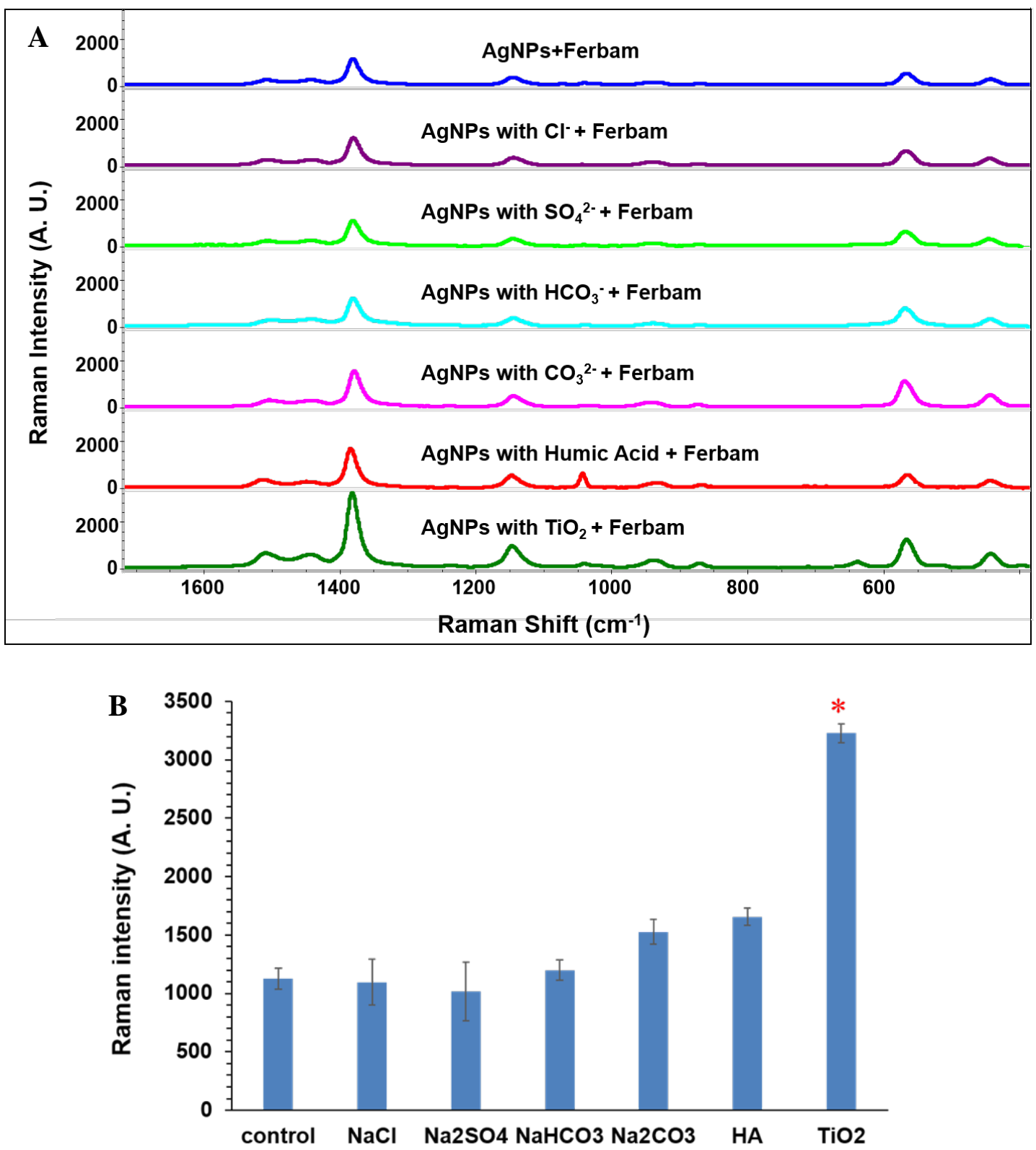

Fig. 5. Effects of matrix constituents in environmental water on SERS detection of AgNPs. [ $\left.\mathrm{Cl}^{-}\right]$ $=177 \mathrm{mg} / \mathrm{L},\left[\mathrm{SO}_{4}{ }^{2-}\right]=480 \mathrm{mg} / \mathrm{L},\left[\mathrm{CO}_{3}{ }^{2-}\right]=300 \mathrm{mg} / \mathrm{L},\left[\mathrm{HCO}_{3}{ }^{-}\right]=305 \mathrm{mg} / \mathrm{L}$, [humic acid, $\left.\mathrm{HA}\right]=$ $20 \mathrm{mg} / \mathrm{L}$ and $\left[\mathrm{TiO}_{2}\right]=50 \mathrm{mg} / \mathrm{L}$. SERS spectra (A) and statistical analysis based on SERS signal intensity at $1382 \mathrm{~cm}^{-1}$ (B). The asterisk means a significant difference from the control (ANOVA, Dunnett's test, $p<0.05)$.

Further, we evaluated the ability of ferbam-assisted SERS approach to detect AgNPs in complex biological sample (i.e., spinach leaves). As clearly seen in Fig. 6, characteristic peaks of ferbam 
enhanced by AgNPs present in spinach leaves indicate that ferbam-assisted SERS was able to probe AgNPs in the biomolecule-rich vegetable matrix. In addition, the Raman intensity of AgNPs-ferbam complexes in spinach juice was elevated as AgNP concentration increased, which shows a similar trend as AgNPs in pond water and confirmed the reliability of ferbam as a good indicator for detecting AgNPs in biological samples. Moreover, a linear curve was built between Raman intensity at $1382 \mathrm{~cm}^{-1}$ and AgNPs concentration, demonstrating the quantitative ability of ferbam-assisted SERS method for AgNPs in complex biological samples. We also examined how AgNP detection was influenced by major biocomponents in spinach, which include proteins as well as chlorophyll and carotenes. The SERS data (Fig. 7) showed that these biomolecules in spinach leaves had statistically insignificant effects on the probing of AgNPs (ANOVA, Dunnett's test, $p<0.05$ ), which reflected the great capability of the ferbam-assisted SERS method for detecting AgNPs in complex bio-matrix.
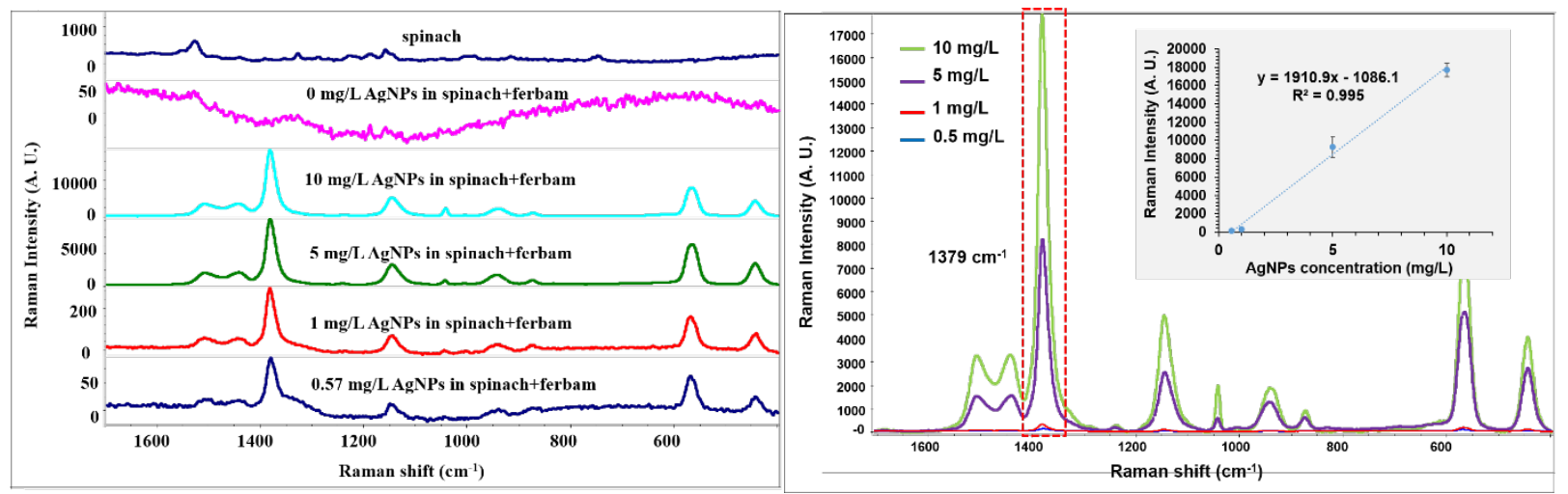

Fig. 6. Detection of different levels of AgNPs in spinach leaves using ferbam-assisted SERS method (Left) and the linear relationship between Raman intensity at $1382 \mathrm{~cm}^{-1}$ and AgNPs concentration (Right). Spinach leaves alone and spinach leaves with the capping solution of AgNPs (2 mM sodium citrate) plus ferbam were used as controls. 

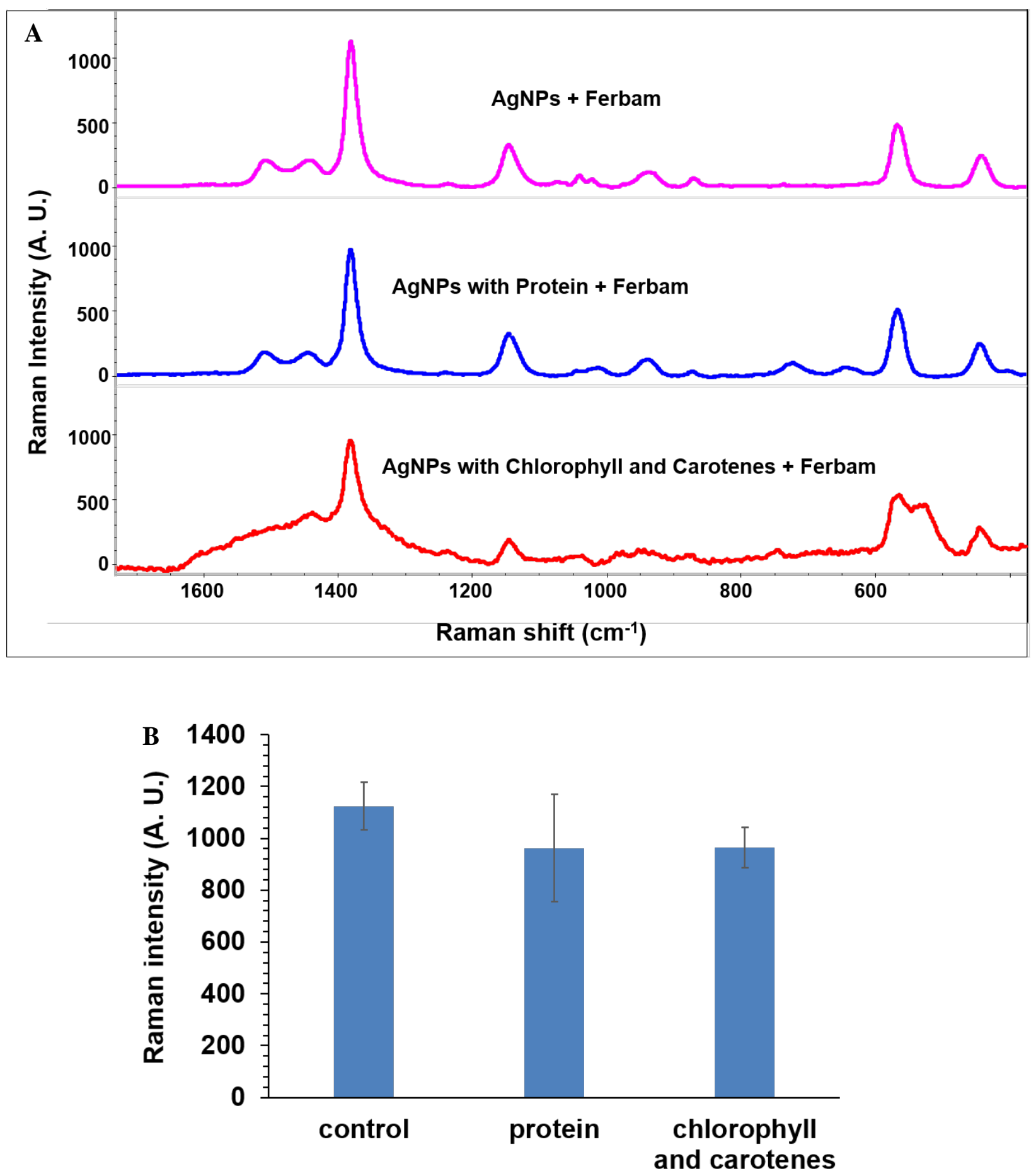

Fig. 7. Effects of matrix constituents in spinach leaves on SERS detection of AgNPs. [protein] = $600 \mathrm{mg} / \mathrm{L}$, [chlorophyll and carotenes] $=1000 \mathrm{mg} / \mathrm{L}$. SERS spectra (A) and statistical analysis based on SERS signal intensity at $1382 \mathrm{~cm}^{-1}$ (B). An asterisk means a significant difference from the control (ANOVA, Dunnett's test, $p<0.05$ ). 


\section{Conclusions}

In summary, among the 7 tested chemicals, ferbam is the best indicator capable of producing distinct and high SERS signals, and binding to the surface of AgNPs strongly enough to resist interfering agents. The underlying mechanism primarily lies in the strong binding ability of ferbam with AgNPs through multiple sulfur atoms. Moreover, the ferbam-assisted SERS method was verified to be effective for detecting AgNPs within natural surface water, indicating that the strong AgNPs-sorbed ability makes ferbam outcompete the common components in pond water. Also, the SERS method assisted by ferbam is a powerful tool to probe AgNPs in vegetable samples in the presence of complex biomolecules. Through this study, we demonstrate the promising potential of the ferbam-assisted SERS method to effectively detect AgNPs in environmental and complex biological samples. However, there are still room and need for improving the sensitivity of SERS detection of AgNPs in complex matrices. When AgNP concentrations reach low enough, as $\mu \mathrm{g} / \mathrm{L}$ and below, the detection can be interfered by matrix components. In order to minimize matrix influence and achieve the rapid detection of trace levels of AgNPs, SERS coupled with various extractions, pre-concentration and phase separation techniques should be investigated in the future.

\section{Acknowledgments}

This study is supported by USDA-NIFA 2015-67017-23070 and USDA-NIFA Hatch program (MAS 00475).

\section{References}

Bartłomiejczyk, T., Lankoff, A., Kruszewski, M., Szumiel, I., 2013. Silver nanoparticles - Allies or adversaries? Ann. Agric. Environ. Med. 20, 48-54.

Bergeson, L.L., 2010. Nanosilver: US EPA’s Pesticide Office Considers How Best to Proceed. Environ. Qual. Manag. 19, 79-85. doi:10.1002/tqem.20255

Doering, W.E., Nie, S., 2003. Spectroscopic Tags Using Dye-Embedded Nanoparticles and Surface-Enhanced Raman Scattering. Anal. Chem. 75, 6171-6176. doi:10.1021/ac034672u

Eom, H.-J., Choi, J., 2010. p38 MAPK activation, DNA damage, cell cycle arrest and apoptosis 
as mechanisms of toxicity of silver nanoparticles in Jurkat T cells. Environ. Sci. Technol. 44, 8337-8342. doi:10.1021/es1020668

Gardea-Torresdey, J.L., Rico, C.M., White, J.C., 2014. Trophic Transfer, Transformation, and Impact of Engineered Nanomaterials in Terrestrial Environments. Environ. Sci. Technol. 48, 2526-2540. doi:10.1021/es4050665

Graham, D., Brown, R., Ewen Smith, W., 2001. SERRS detection of PNA and DNA labelled with a specifically designed benzotriazole azo dye. Chem. Commun. 1002-1003. doi:10.1039/B102241P

Guo, H., Xing, B., He, L., 2016. Development of a filter-based method for detecting silver nanoparticles and their heteroaggregation in aqueous environments by surface-enhanced Raman spectroscopy. Environ. Pollut. 211, 198-205. doi:http://dx.doi.org/10.1016/j.envpol.2015.12.049

Guo, H., Zhang, Z., Xing, B., Mukherjee, A., Musante, C., White, J.C., He, L., 2015. Analysis of Silver Nanoparticles in Antimicrobial Products Using Surface-Enhanced Raman Spectroscopy (SERS). Environ. Sci. Technol. 49, 4317-4324. doi:10.1021/acs.est.5b00370

Hawthorne, J., De la Torre Roche, R., Xing, B., Newman, L.A., Ma, X., Majumdar, S., GardeaTorresdey, J., White, J.C., 2014. Particle-Size Dependent Accumulation and Trophic Transfer of Cerium Oxide through a Terrestrial Food Chain. Environ. Sci. Technol. 48, 13102-13109. doi:10.1021/es503792f

Haynes, C.L., McFarland, A.D., Van Duyne, R.P., 2005. Surface-enhanced Raman spectroscopy. Anal. Chem. 77, 338a-346a. doi:10.1021/ac053456d

Huh, Y., Chung, A., Erickson, D., 2009. Surface enhanced Raman spectroscopy and its application to molecular and cellular analysis. Microfluid. Nanofluidics 6, 285-297. doi:10.1007/s10404-008-0392-3

Johnson, R.L., Holmquist, D., Redding, K., McDaniel, C., 2011. Water Quality with Vernier: Chloride and Salinity. Available at http://www2.vernier.com/sample_labs/WQV-15-COMPchloride_salinity.pdf (February 2016).

Kim, S., Ryu, D.Y., 2013. Silver nanoparticle-induced oxidative stress, genotoxicity and apoptosis in cultured cells and animal tissues. J. Appl. Toxicol. 33, 78-89. doi:10.1002/jat.2792

Lee, P.C., Meisel, D., 1982. Adsorption and surface-enhanced Raman of dyes on silver and gold sols. J. Phys. Chem. 86, 3391-3395. doi:10.1021/j100214a025

Levard, C., Hotze, E.M., Lowry, G. V., Brown, G.E., 2012. Environmental transformations of silver nanoparticles: Impact on stability and toxicity. Environ. Sci. Technol. 46, 6900-6914. doi:10.1021/es2037405

Lower, S.K., 1999. Carbonate equilibria in natural waters Available at http://www.chem1.com/acad/webtext/pdf/c3carb.pdf (December 2015).

Majedi, S.M., Lee, H.K., 2016. Recent advances in the separation and quantification of metallic nanoparticles and ions in the environment. TrAC - Trends Anal. Chem. 75, 183-196. doi:10.1016/j.trac.2015.08.009

Michigan Department of Environmental Quality, 1994. Total Suspended Solids. Available at 
http://www.michigan.gov/documents/deq/wb-npdes-TotalSuspendedSolids_247238_7.pdf (December 2015).

Mwilu, S.K., Siska, E., Baig, R.B.N., Varma, R.S., Heithmar, E., Rogers, K.R., 2014. Separation and measurement of silver nanoparticles and silver ions using magnetic particles. Sci. Total Environ. 472, 316-23. doi:10.1016/j.scitotenv.2013.10.077

Nikanorov, A.M., Brazhnikova, L. V., Sketches, B., 2009. Water chemical composition of rives, lakes and wetlands. In: Khublaryan, M.G. (Ed.). Types and Properties of Water. Vol. 2. EOLSS Co. Ltd. pp. 42-80. Available at http://www.eolss.net/sample-chapters/c07/e203.pdf (December 2015).

Pavia, D.L., Lampman, G.M., Kriz, G.S., Engel, R.G., 1999. Isolation of Chlorophyll and Carotenoid Pigments from Spinach, In: Introduction to Organic Laboratory Techniques: A Microscale Approach 3rd Edition. Saunders College Publishing: New York, NY, pp. 1-7.

Rodrigues, A., Brito, A., Janknecht, P., Proença, M.F., Nogueira, R., 2009. Quantification of humic acids in surface water: effects of divalent cations, $\mathrm{pH}$, and filtration. J. Environ. Monit. 11, 377-382. doi:10.1039/B811942B

Sánchez-Cortés, S., Vasina, M., Francioso, O., García-Ramos, J. V, 1998. Raman and surfaceenhanced Raman spectroscopy of dithiocarbamate fungicides. Vib. Spectrosc. 17, 133-144. doi:10.1016/S0924-2031(98)00025-3

Schluesener, J.K., Schluesener, H.J., 2013. Nanosilver: Application and novel aspects of toxicology. Arch. Toxicol. 87, 569-576. doi:10.1007/s00204-012-1007-z

Tiede, K., Boxall, A.B. a, Tear, S.P., Lewis, J., David, H., Hassellov, M., 2008. Detection and characterization of engineered nanoparticles in food and the environment. Food Addit. Contam. Part A. Chem. Anal. Control. Expo. Risk Assess. 25, 795-821. doi:10.1080/02652030802007553

Wang, W., Vignani, R., Scali, M., Cresti, M., 2006. A universal and rapid protocol for protein extraction from recalcitrant plant tissues for proteomic analysis. Electrophoresis 27, 27822786. doi:10.1002/elps.200500722

WHO, 2004. Sulfate in Drinking-water Background document for development of WHO Guidelines for Drinking-water Quality. Available at http://www.who.int/water_sanitation_health/dwq/chemicals/sulfate.pdf (December 2015).

Wijnhoven, S.W.P.P., Peijnenburg, W.J.G.M.G.M., Herberts, C. a., Hagens, W.I., Oomen, A.G., Heugens, E.H.W.W., Roszek, B., Bisschops, J., Gosens, I., Van De Meent, D., Dekkers, S., De Jong, W.H., van Zijverden, M., Sips, A.J. a. M., Geertsma, R.E., 2009. Nano-silver - a review of available data and knowledge gaps in human and environmental risk assessment. Nanotoxicology. doi:10.1080/17435390902725914

Zheng, J., Pang, S., Labuza, T.P., He, L., 2013. Semi-quantification of surface-enhanced Raman scattering using a handheld Raman spectrometer: a feasibility study. Analyst 138, 70757078. doi:10.1039/C3AN01450A 